\title{
The role of the ERKI/2 pathway in simvastatin- loaded nanomicelles and simvastatin in regulating the osteogenic effect in MG63 cells
}

This article was published in the following Dove Press journal: International Journal of Nanomedicine

\author{
Mao Niu',* \\ Xianling Feng ${ }^{2, *}$ \\ Lei Zhou ${ }^{3}$ \\ 'Department of Stomatology, School \\ of Medical Technology and Nursing, \\ Shenzhen Polytechnic, Shenzhen, \\ 5I8055, China; ${ }^{2}$ Department of \\ Pathology, School of Medical, \\ Shenzhen University, Shenzhen, \\ 5I 8060, China; ${ }^{3}$ Center of Oral \\ Implantology, Guangdong Provincial \\ Stomatological Hospital, Southern \\ Medical University, Guangzhou, \\ 510280 , China \\ *These authors contributed equally \\ to this work
}

Objectives: The present study aimed to clarify the role of the ERK1/2 pathway in simvastatin (SV)-loaded nanomicelles (SVNs)- and SV-mediated promotion of cell osteogenic differentiation and explore the molecular mechanisms by which SVNs exhibited a greater efficacy in promoting osteogenic differentiation than SV.

Materials and methods: SVNs were synthesized using a dialysis method. MG63 cells were treated with $2.5,0.25$, and $0.025 \mu \mathrm{mol} / \mathrm{L}$ of the drug. The optimal drug dosage was determined by examining the proliferative activity and ALP activity of the MG63 cells. Subsequently, Western blot analysis was performed to analyze the levels of the phosphorylated ERK1/2 proteins in each experimental group at various time points. Finally, the inhibitor PD98059 was used to effectively inhibit the ERK1/2 pathway. The resulting changes in the proliferative activity of MG63 cells and the osteogenesis-related markers were analyzed.

Results: The SVNs synthesized in the present study had a mean diameter of $27 \mathrm{~nm}$. The encapsulation and drug-loading efficiencies were $52.03 \% \pm 4.05 \%$ and $9.42 \% \pm 0.66 \%$, respectively. SVNs and SV exhibited optimum osteogenesis-promoting effects when the drugs were administered at a concentration of $0.25 \mu \mathrm{mol} / \mathrm{L}$. The drug-induced activation of the ERK1/2 pathway reached a peak at 15 minutes after administration and then declined rapidly. From 24 hours to 7 days, SVNs and SV exerted an inhibitory effect on the ERK1/2 pathway rather than an activating effect. Throughout the whole experimental process, the regulatory effect of SVNs on the ERK1/2 pathway was significantly greater than that of SV. Inhibition of the ERK1/2 pathway by PD98059 markedly reduced the proliferative activity of the cells in all experimental groups. In addition, the ALP activity and the expression levels of the osterix (OSX) and osteocalcin (OC) proteins were drastically increased.

Conclusion: SVNs significantly increased the effect of SV-induced osteogenic differentiation by strongly inhibiting the ERK1/2 pathway.

Keywords: simvastatin-loaded nanomicelles, ERK1/2 pathway, dental implant restoration, osteogenic effect

\section{Introduction}

Long-term tooth loss can lead to massive resorption of alveolar bone. The bone height and width are insufficient for dental implantation. At present, there are several treatments to promote bone regeneration, such as autologous or allogeneic bone grafting, bone tissue engineering, and application of bone substitute. ${ }^{1-3}$ Furthermore, some small molecule drugs have been found to promote bone regeneration. Mundy et $\mathrm{al}^{4}$ reported that statins, especially simvastatin (SV), enhanced the mRNA expression of BMP-2 in osteoblasts in vitro. In addition, subcutaneous injection of SV significantly
Correspondence: Lei Zhou

Center of Oral Implantology, Guangdong Provincial Stomatological Hospital,

Southern Medical University, 366 South Jiang Nan Road, Hai Zhu District,

Guangzhou 510280 , China

Tel +862084233801

Fax +86 2084433177

Email zho668@263.net
International Journal of Nanomedicine 2018:13 8165-8178

(c) (1) (8) $\odot 2018$ Niu et al. This work is published and licensed by Dove Medical Press Limited. The full terms of this license are avalable at https:/www.doverpess.com/terms.php cc. hereby accept the Terms. Non-commercial uses of the work are permitted without any further permision from Dove Medical Press Limited, provided the work is properly attributed. For permision for commercial use of this work, please see paragraphs 4.2 and 5 of our Terms (https://www. doverperess.com/terms.php). 
promoted new bone formation in the mouse skull. An increasing number of studies have shown that SV promotes bone formation. ${ }^{5-7}$ Our previous study also showed that an appropriate concentration of SV can increase osteogenic activity of human periodontal ligament cells. ${ }^{8}$ Thus, SV has broad application prospects in the repair of bone defects, including those in the jaw region.

However, SV is a lipid-soluble drug and is poorly soluble in water. In addition, SV exhibits a strong first-pass effect and is rapidly eliminated from the body. SV has a short plasma half-life and can be absorbed quickly. Systemic administration of high doses of SV may induce adverse reactions, such as liver failure, kidney disease, and rhabdomyolysis..$^{9,10}$ Therefore, the extremely low bioavailability of SV to the bone and the potential side effects of SV seriously limit its application in promoting maxillary and mandibular osteogenesis.

Nanocarriers are capable of carrying hydrophobic drugs. Application of nanocarriers allows the drugs to evade capture by the reticuloendothelial system. Therefore, nanocarriers possess advantages in drug delivery, such as enhancement of the bioavailability, prolongation of the action time, and reduction of the side effects. In a previous study, we synthesized SV-loaded nanomicelles (SVNs) using a dialysis method, which greatly prolonged the duration of SV release, significantly promoted the expression of osteogenic markers (such as runt-related transcription factor 2 [Runx2], ALP, osteocalcin [OC], and collagen I [Col I]) in osteoblasts, and considerably enhanced the osteogenic differentiationpromoting effect of SV in vitro. ${ }^{11} \mathrm{We}$ also confirmed by in vivo experiments that the nanoformulations of SV showed a stronger effect on the formation of new bone in a rabbit skull defect area than SV. ${ }^{12}$ To date, the potential mechanisms by which SVNs significantly enhance the efficacy of SV in promoting osteogenesis have not been reported.

Osteogenesis-related signaling pathways transmit extracellular molecular signals across the plasma membrane into the cells, thereby regulating cell proliferation and osteogenic differentiation. Mitogen activated protein kinases (MAPKs) widely exist in eukaryotic cells, and MAPK-mediated signaling pathways play important regulatory roles in cell proliferation and differentiation. ERK1/2 were the first members of the MAPK family to be characterized in the early 1990 s. ${ }^{13,14}$ The process of ERK1/2 pathway-mediated signal transduction can be briefly summarized as follows: extracellular stimuli bind to receptor tyrosine kinases, which promote the activation of Ras-GDP through guanyl nucleotide exchange. The resulting active form of Ras-GTP binds to the Ras-binding domain of
Raf and activates Raf via various pathways. Activated Ras and Raf activate MEK1/2 by phosphorylating the serine residue in the activation domain of MEK1/2. Activated MEK1/2 phosphorylates the tryptophan/threonine (Try/Thr) residues adjacent to a tyrosine residue, thereby activating ERK1/2. Activated ERK1/2 pass through the nuclear envelope, translocating from the cytoplasm to the nucleus. In the nucleus, ERK1/2 act on the downstream transcription factors to promote the transcription and expression of target genes, thereby regulating the biological properties of the cells. ${ }^{15,16}$

The ERK1/2 pathway plays an important role in the early proliferation and differentiation of osteoblasts. Some scholars have found that some substances (such as laminin, fibroblast growth factor 2 (FGF2), chrysin, etc) can regulate osteoblasts differentiation via the ERK1/2 pathway. ${ }^{17-19}$ The number of studies focusing on the role of the ERK1/2 pathway in the regulation of osteogenesis has increased. However, controversy remains regarding whether the ERK1/2 pathway promotes or inhibits osteogenesis.

In addition, SV regulates the ERK1/2 pathway by affecting the activity of Ras, thereby regulating the biological properties of the cells. Ras, which is the upstream activator protein of the ERK1/2 pathway, exists in two forms: the GTP-bound active form and the GDP-bound resting form. Generally, Ras is located in the cytoplasm when it is in the resting state. Once activated, Ras translocates to the plasma membrane. Activated Ras is a prenylated protein and is a product of the mevalonate (MVA) pathway. 3-hydroxy-3methylglutaryl-coenzyme A (HMG-CoA) reductase is a key enzyme in the MVA pathway. As an HMG-CoA reductase inhibitor, SV prevents the isoprenylation of Ras and suppresses the activation of Ras by inhibiting the MVA pathway, thereby inhibiting ERK1/2 pathway activation. ${ }^{20}$ However, certain studies have shown that $\mathrm{SV}$ has an activating effect on ERK1/2 pathway. Therefore, there are also controversies surrounding the regulatory effects of SV on ERK1/2.

We hypothesize that the ERK1/2 pathway plays an important role in SVNs- and SV-mediated promotion of osteoblast differentiation. In addition, SVNs exert a strong regulatory effect on the ERK1/2 pathway due to their unique nanoeffects, thereby exhibiting a more potent osteogenesispromoting effect than that of SV. To test our hypothesis, we first examined the regulatory effects of appropriate concentrations of SVNs and SV on the ERK1/2 pathway in MG63 cells. Subsequently, we inhibited the ERK1/2 pathway using an inhibitor. The changes in the proliferative activity of MG63 cells and the relevant osteogenic factors (such as OSX, ALP, and OC) were then examined to clarify the role 
of the ERK1/2 pathway in the SVN- and SV-mediated promotion of osteoblast differentiation. Moreover, the potential molecular mechanisms by which SVNs significantly enhance the osteogenic efficacy of SV were explored. Our results provide a scientific basis for the subsequent design optimization, targeted modification, and clinical application of SVNs.

\section{Materials and methods}

\section{Preparation and characterization of SVNs}

Based on the previous experience in preparing nanomicelles in our group, ${ }^{11} \mathrm{SVNs}$ (methoxy polyethy-lene glycol- Polylactic acid-SV [mPEG-PLA-SV]) were prepared using a dialysis method. In short, $10 \mathrm{mg}$ of mPEG-PLA ( $\mathrm{Mn}=5,000-3,000$; Jinan Daigang Biomaterial Co., Ltd., Shandong, China) and $2 \mathrm{mg}$ of SV (National Institutes for Food and Drug Control, Beijing, China) were dissolved in $2 \mathrm{~mL}$ of acetonitrile (Thermo Fisher Scientific, Waltham, MA, USA) and slowly added dropwise into $12 \mathrm{~mL}$ of purified water. The mixture was stirred for 1 hour at room temperature and then dispersed via ultrasonication for 5 minutes. Finally, the above solution was dialyzed for 7 hours. The drug-free nanomicelles (DFNs) were also prepared in a similar way in the absence of SV.

The particle sizes of SVNs and DFNs were measured using a Zetasizer instrument (Mastersizer 2000; Malvern Instruments, Malvern, UK). Nanomicelle morphology was observed with a transmission electron microscope (TEM; HT7700; Hitachi Ltd., Tokyo, Japan). HPLC (LC-20AD; Shimazu Corporation, Kyoto, Japan) system was used to determine the drug-loading content and drug-entrapment efficiency.

\section{In vitro SV release}

SVNs were sealed in a dialysis bag and incubated in $4 \%$ human serum albumin solution at $37^{\circ} \mathrm{C}$ and $50 \mathrm{rpm}$. The same amount of free SV was dialyzed under the same conditions as the control. At predetermined time intervals, $12 \mathrm{~mL}$ of the samples was withdrawn and replaced with $12 \mathrm{~mL}$ of fresh release medium. The SV concentration was analyzed using the HPLC system.

\section{Cell culture and experimental group}

The human osteoblast-like MG63 cells were purchased from the Cell Bank of the Chinese Academy of Sciences, Shanghai, China. The MG63 cells were cultured in DMEM (Thermo Fisher Scientific) with 10\% FBS (Thermo Fisher Scientific) and $1 \%$ penicillin-streptomycin (HyClone, Logan, UT, USA) at $37^{\circ} \mathrm{C}$ in a humidified incubator with $5 \% \mathrm{CO}_{2}$. The medium was refreshed every 3 days.

The experiment was divided into four groups: the SVN group (SVNG), the SV group (SVG) as the positive control, the DFN group (DFNG), and the blank control group (BCG) as the negative control.

\section{Determination of the appropriate SV concentration}

According to the preliminary results of our group, the SV in the SVNG and SVG was dissolved and diluted to three groups with high $(2.5 \mu \mathrm{mol} / \mathrm{L})$, medium $(0.25 \mu \mathrm{mol} / \mathrm{L})$, and low $(0.025 \mu \mathrm{mol} / \mathrm{L})$ concentrations in the complete medium. Equal concentrations of DFNs were also prepared. The cell proliferation and ALP activity were measured to determine the optimal dosing concentration.

\section{Cell proliferation}

MG63 cells were seeded onto 24-well plates at $10^{4}$ cells per well and cultured with the different drug formulations ( $500 \mu \mathrm{L} /$ well) for 1,3 , and 7 days. Then, culture medium was removed and serum-free medium $(500 \mu \mathrm{L} /$ well $)$ was added. The plate was incubated for 2 hours at $37^{\circ} \mathrm{C}$ in a humidified 5\% $\mathrm{CO}_{2}$ atmosphere. Then, a 3-(4,5-dimethylthiazol2-yl)-5-(3-carboxymethoxyphenyl)-2-(4-sulfophenyl)2H-tetrazolium (MTS) Assay kit (Biovision Inc., CA, USA) was used to measure cell proliferation. First, $100 \mu \mathrm{L}$ of MTS solution was mixed with culture medium in each well, $100 \mu \mathrm{L}$ of the mixture was pipetted into each well of the 96-well plate, and absorbance was measured at 30-minute intervals at $490 \mathrm{~nm}$ using a microplate reader (Tecan Trading AG, Switzerland).

\section{ALP activity}

MG63 cells were seeded onto 24 -well plates at $10^{4}$ cells/well. After 7 days of culturing, culture medium was removed, and $50 \mu \mathrm{L} /$ well of Laemmli sample buffer together with protease inhibitor $(50: 1 \mathrm{v} / \mathrm{v})$ was added to lyse the cells. Then, samples were centrifuged at $10,000 \mathrm{rpm}$ at $4^{\circ} \mathrm{C}$. Next, $10 \mu \mathrm{L}$ of supernatants was pipetted to measure the protein concentration using a bicinchoninic acid (BCA) protein assay kit (Thermo Fisher Scientific). The absorbance of the solution was measured at $562 \mathrm{~nm}$, and the amount of total protein was calculated using a generated calibration curve. Meanwhile, $30 \mu \mathrm{L}$ of supernatant was pipetted to measure ALP activity, and the absorbance of the solution at $520 \mathrm{~nm}$ was measured. The amount of ALP was normalized to the amount of total proteins synthesized to determine ALP activity. 


\section{Cell cycle and apoptosis}

MG63 cells were seeded in $6 \mathrm{~cm}$ Petri dishes at $1 \times 10^{6} / \mathrm{dish}$. After 24 hours of incubation, the cells were completely adhered, and the corresponding drugs were added to the MG63 cells according to the experimental group. The experiment was terminated at 24 hours after dosing, and the effects of drugs on the cell cycle and apoptosis of MG63 cells were measured by flow cytometry.

\section{Cell cycle}

A cell cycle detection kit (Keygen Biotech, Jiangsu, China) was used to detect the cell cycle. The culture medium was removed, the cells were washed twice with precooled PBS, and $1 \mathrm{~mL}$ of $0.25 \%$ EDTA-trypsin was added to digest the cells. The cells were collected by centrifugation at $1,000 \times$ $g$ at $4{ }^{\circ} \mathrm{C}$ for 5 minutes. After the supernatant was removed, the cells were resuspended with $1 \mathrm{~mL}$ of precooled Buffer A and collected by centrifugation again. Then, the cells were resuspended with $100 \mu \mathrm{L}$ of precooled Buffer A, slowly dripped into $900 \mu \mathrm{L}$ of precooled $70 \%$ ethanol, and fixed at $-20^{\circ} \mathrm{C}$ for at least 12 hours. The cells were collected by centrifugation again, washed with precooled Buffer A to remove the ethanol, resuspended in $500 \mu \mathrm{L}$ of Buffer $\mathrm{A}$, and mixed with RNase $\mathrm{A}$ at $37^{\circ} \mathrm{C}$ for 30 minutes. The samples were stained with propidium iodide (PI) at room temperature for 30 minutes in dark conditions and analyzed by flow cytometry.

\section{Cell apoptosis}

An Annexin V-FITC/PI Apoptosis Detection Kit (BD, Becton, Dickinson and Company, NJ, USA) was used to detect the apoptotic cells. The cells were collected using trypsin without EDTA by centrifugation and resuspended with $300 \mu \mathrm{L} 1 \times$ binding buffer. Then, $100 \mu \mathrm{L}$ of cell suspension was pipetted into a culture tube, and $5 \mu \mathrm{L}$ of Annexin V-FITC was added to each tube and incubated for 15 minutes at room temperature. Next, $5 \mu \mathrm{L}$ of PI was added to the cells for 5 minutes at room temperature without light. After addition of $400 \mu \mathrm{L}$ of $1 \times$ binding buffer to each tube, cell apoptosis was analyzed by flow cytometry.

\section{Western blotting}

MG63 cells were seeded onto 6-well plates at $5 \times 10^{5}$ cells/ well and cultured with the corresponding drugs according to the experimental group. The protein levels of phosphorylated ERK1/2 ( $p$-ERK1/2; 5, 15, 30 minutes and 1,7 , and 14 days), total ERK1/2 ( $t$-ERK1/2; 5, 15, 30 minutes and 1, 7, and 14 days), OSX ( 7 days), and OC (14 days) were determined by Western blot analysis. The following steps were performed: cultured cells were washed twice with ice-cold PBS, and then, the total proteins were extracted from the cells using RIPA lysis buffer containing a protease inhibitor (Cell Signaling Technology Inc., MA, USA) and phosphatase inhibitors (Cell Signaling Technology Inc.). The protein concentrations were determined using a BCA protein assay (Pierce BCA Protein Assay Kit; Thermo Fisher Scientific). An equal amount of protein $(20 \mu \mathrm{g} / \mathrm{lane})$ was separated by $10 \%$ SDS-PAGE and then transferred to polyvinylidene difluoride membranes (EMD Millipore, Billerica, MA, USA). After the membranes were blocked with 5\% BSA in TBS with Tween-20 for 60 minutes, they were incubated with primary antibodies at $4{ }^{\circ} \mathrm{C}$ overnight. Next, the membranes were incubated for 60 minutes at room temperature with a horseradish peroxidase-linked secondary antibody. The bands were visualized using an enhanced chemiluminescence detection system. The quantification of protein was calculated by densitometry analysis using ImageJ software. The primary antibodies used were specific for $p$-ERK1/2 (1:3,000 dilution; Cell Signaling Technology Inc.), $t$-ERK1/2 (1:250 dilution; Cell Signaling Technology Inc.), OSX (1:1,500 dilution; Abcam, Cambridge, UK), OC (1:1,500 dilution; Abcam), and GAPDH (1:1,500 dilution; Cell Signaling Technology Inc.).

\section{Treatment with PD98059}

To clarify the role of the ERK1/2 pathway in MG63 cell proliferation and osteogenic differentiation, we pretreated the cells with PD98059 (50 $\mu \mathrm{M}$; Cell Signaling Technology Inc.) for 30 minutes, followed by incubation with the corresponding drugs according to the experimental group. The changes in cell proliferation (1 day), cell cycle (1 day), cell apoptosis (1 day), ALP activity (7 days), and the protein expression levels of $p$-ERK1/2 (1, 7, and 14 days), $t$-ERK1/2 (1, 7, and 14 days), OSX (7 days), and OC (14 days) were determined by the same experimental methods as described above.

\section{Statistical analyses}

Statistical analyses were performed using SPSS Version 19.0 (IBM Corp., Armonk, NY, USA). All data are shown as the mean \pm SD from at least three independent experiments and were analyzed by repeat measures ANOVA and Student's $t$-test.

\section{Results Characterization of SV-loaded and blank nanomicelles}

The mean diameter of the SVNs was determined with dynamic light scattering (DLS) and found to be $\sim 27 \mathrm{~nm}$ 
A

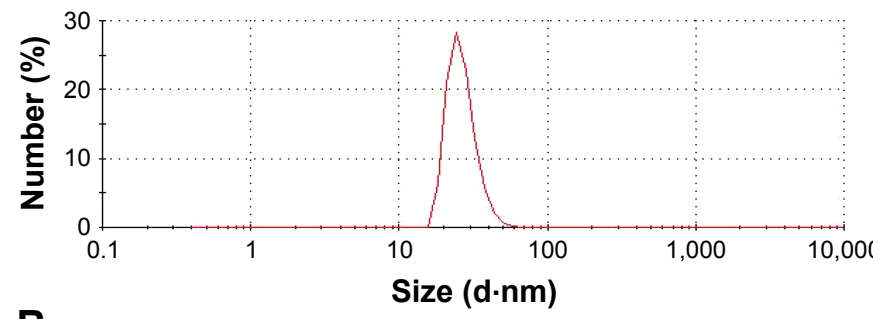

B

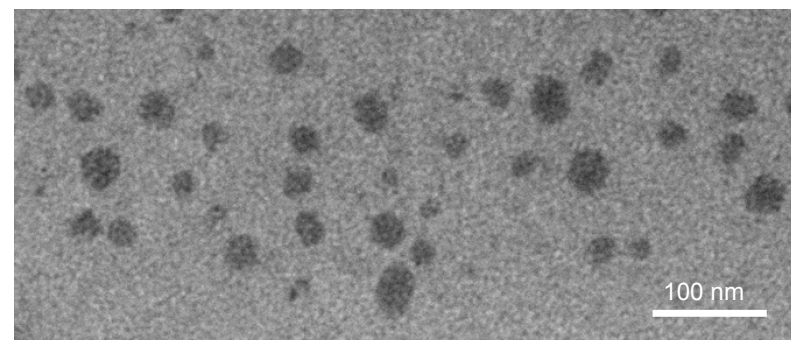

C

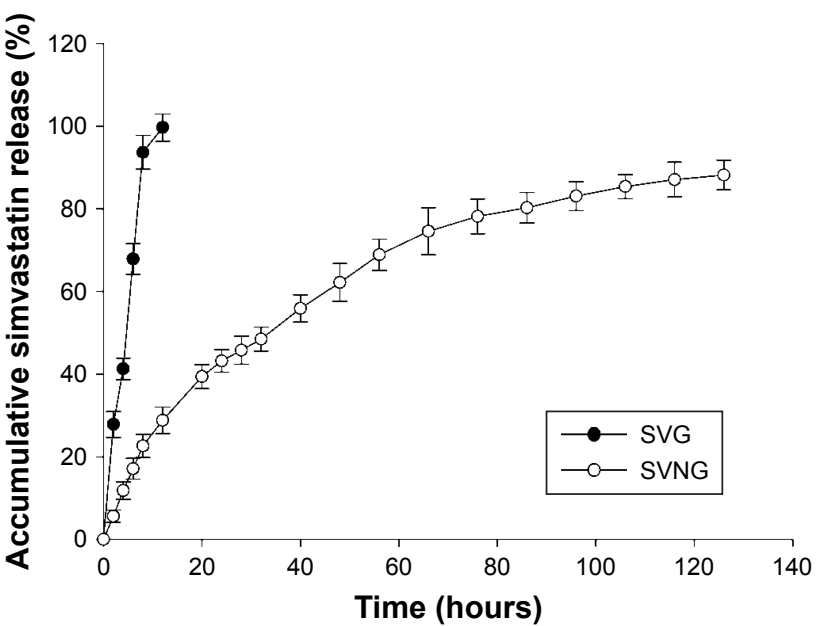

Figure I The characteristics of simvastatin-loaded nanomicelles.

Notes: (A) The particle size of simvastatin-loaded nanomicelles was measured using a Zetasizer instrument. (B) Simvastatin-loaded nanomicelle morphology was observed with a TEM. (C) The in vitro cumulative release profiles of simvastatin from simvastatin-loaded nanomicelles using human serum albumin as a dissolution medium by a dynamic dialysis method. The simvastatin concentration was measured via HPLC at an ultraviolet absorbance of $238 \mathrm{~nm}$. The results are the mean values of three independent measurements $( \pm S D)$.

Abbreviations: SD, standard deviation; SVG, simvastatin group; SVNG, simvastatin-loaded nanomicelles group; TEM, transmission electron microscope.

(Figure 1A). The SVNs were nearly spherical in shape based on the TEM results (Figure 1B). The micelle sizes determined by TEM varied but were $\sim 30 \mathrm{~nm}$, which is consistent with the DLS measurements. Under $20 \%$ theoretical drug-loading capacity conditions, the SVNs presented an encapsulation ratio and drug-loading efficiency of $52.03 \% \pm 4.05 \%$ and $9.42 \% \pm 0.66 \%$, respectively. These nanomicelles were selected for subsequent in vitro release tests and experiments to evaluate their osteogenic effects.

\section{In vitro SV release}

The in vitro cumulative release profiles of SV from the nanomicelles are shown in Figure 1C and clearly indicate controlled release. The results demonstrated that the free SV was nearly completely released at 12 hours, whereas only $\sim 30 \%$ of the total SV had been released from the nanomicelles, and release was sustained until 126 hours, at which point the level was 10 times more than that observed with free SV.

\section{The appropriate SV concentration \\ Cell proliferation}

Figure 2A shows the proliferation of MG63 cells incubated with the drug formulations for 1,3 , and 7 days. The results showed that the number of MG63 cells increased significantly from 1 to 7 days in all experimental groups. These results indicate that all groups of cells underwent proliferation. Throughout the whole experimental process, the proliferative activity of the MG63 cells was significantly inhibited in the experimental groups compared with the BCG. At an SV concentration of $0.25 \mu \mathrm{mol} / \mathrm{L}$, cell viability was significantly reduced in the SVNG compared to the SVG. However, at an $\mathrm{SV}$ concentration of $2.5 \mu \mathrm{mol} / \mathrm{L}$, massive cell death occurred in both the SVNG and the SVG on the third day (Figure 2B and $\mathrm{C}$ ). The results indicate that a high concentration of SV was toxic to the cells. In addition, the number of cells in the SVNG was significantly greater than that in the SVG on the third and seventh days (Figure 2C), indicating that encapsulation of SV inside nanocarriers could reduce the cytotoxicity of high concentrations of SV.

\section{ALP activity}

The osteoblastic differentiation of the MG 63 cells was evaluated by measuring ALP activity after culture with the drug formulations for 7 days. As shown in Figure 2D, except for the SVG treated with $0.025 \mu \mathrm{mol} / \mathrm{L} \mathrm{SV}$, the SVNGs and SVGs exhibited significantly greater cellular ALP activities than the BCG. In addition, at any given SV concentration, cellular ALP activity was significantly greater in the SVNG than in the SVG.

The analysis of the cell proliferation and ALP activity in the experimental groups showed that both SVNs and SV significantly inhibited the proliferative activity of MG63 cells and strongly promoted the differentiation of MG63 cells when administered at appropriate concentrations. These effects were particularly pronounced when the SV concentration was 


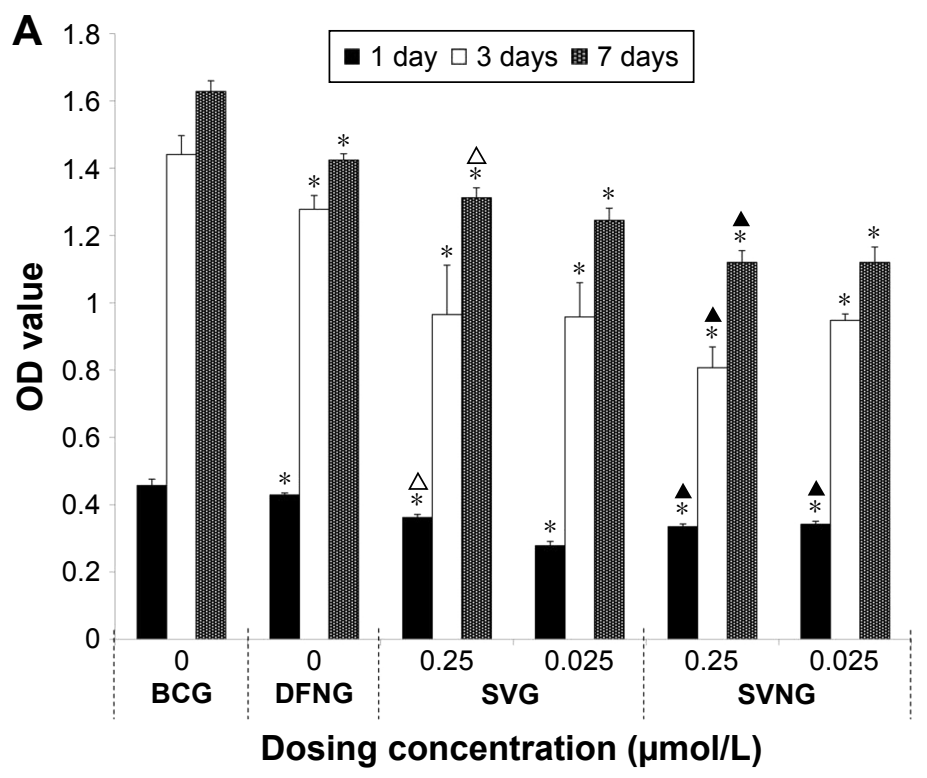

B
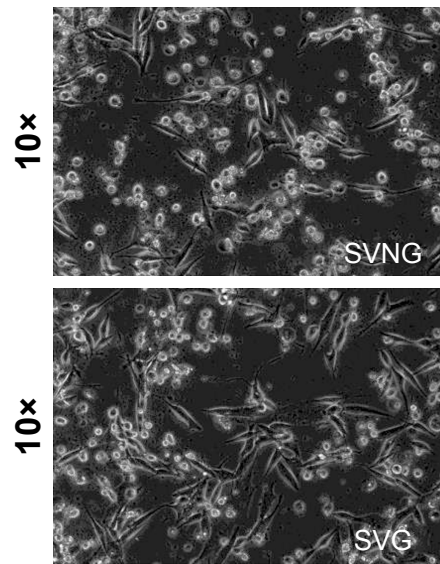

Dosing concentration ( $\mu \mathrm{mol} / \mathrm{L})$
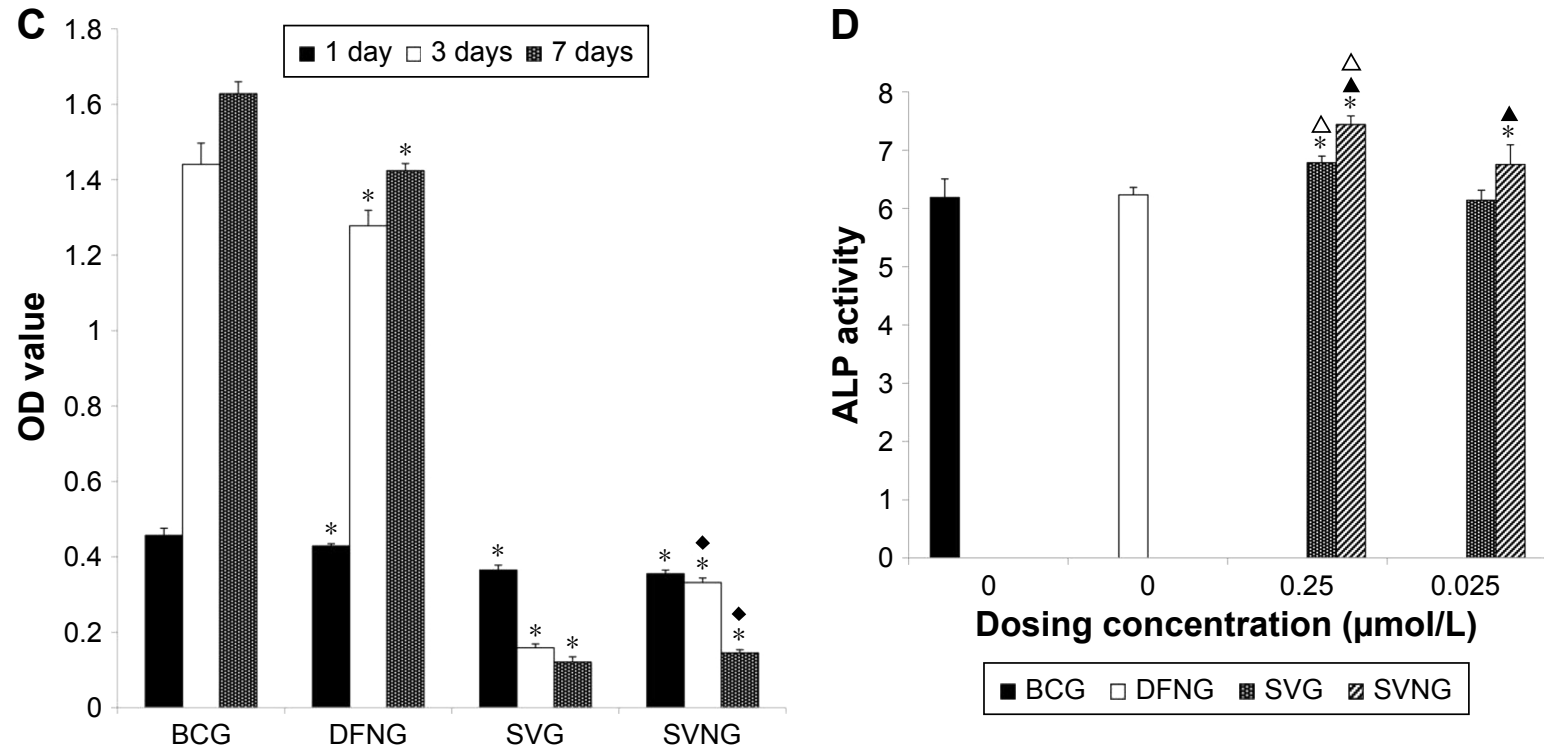

- BCG $\square$ DFNG 国 SVG चSVNG

Figure 2 The effects of different concentrations of SVNs and SV on MG63 cells.

Notes: When the dosing concentration was 0.25 and $0.025 \mu \mathrm{mol} / \mathrm{L}$, the effects of SVNs and SV on the cellular proliferation activity (A) and ALP activity were determined (D). When the dosing concentration was $2.5 \mu \mathrm{mol} / \mathrm{L}$, the effects of SVNs and SV on cell proliferation activity were determined (C), and massive cell death occurred in both the SVNG and the SVG as shown by an inverted microscope on the third day (B). The results are represented as the mean values of three independent measurements $( \pm \mathrm{SD})$. $* P<0.05$ vs BCG; ${ }^{\wedge} P<0.05$ SVNG vs SVG $(0.25 \mu \mathrm{mol} / \mathrm{L}) ;{ }^{\Delta} P<0.05$ SVNG vs SVG $(0.025 \mu \mathrm{mol} / \mathrm{L}) ;{ }^{\bullet} P<0.05 \mathrm{SVNG}$ vs SVG $(2.5 \mu \mathrm{mol} / \mathrm{L})$.

Abbreviations: BCG, blank control group; DFNG, drug-free nanomicelles group; SD, standard deviation; SV, simvastatin; SVG, simvastatin group; SVNs, simvastatin-loaded nanomicelles; SVNG, simvastatin-loaded nanomicelles group.

$0.25 \mu \mathrm{mol} / \mathrm{L}$. Therefore, a drug concentration of $0.25 \mu \mathrm{mol} / \mathrm{L}$ was used in the subsequent experiments.

\section{Effects of SVNs and SV on the ERKI/2 pathway}

In the present study, the effects of SVNs and SV on the ERK1/2 pathway were examined at various time points. After MG63 cells were exposed to SVNs or SV medium for 5, 15, 30 minutes and 1, 7, and 14 days, we measured the phosphorylation levels of ERK1/2 proteins. The results of the Western blot analysis showed that exposure to either SVNs or SV for 15 minutes significantly increased the phosphorylated ERK1/2 protein levels (Figure 3A). However, SVNs exerted a more potent effect than SV (Figure 3A). After 15 minutes, the phosphorylation levels of ERK1/2 decreased gradually (Figure 3A). As drug exposure became prolonged (1, 7, and 14 days), both SVNs and SV exhibited a significant, sustained inhibitory effect on the expression of the phosphorylated 
A

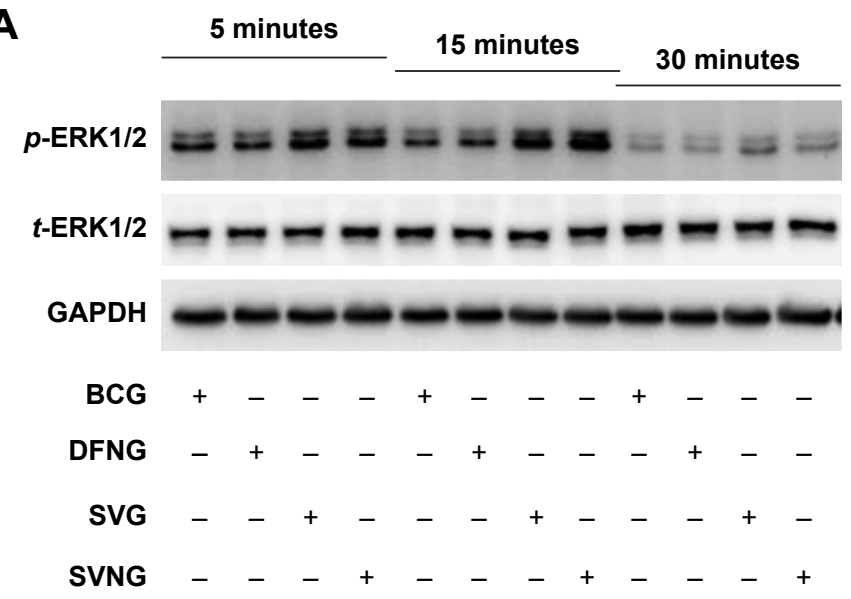

B

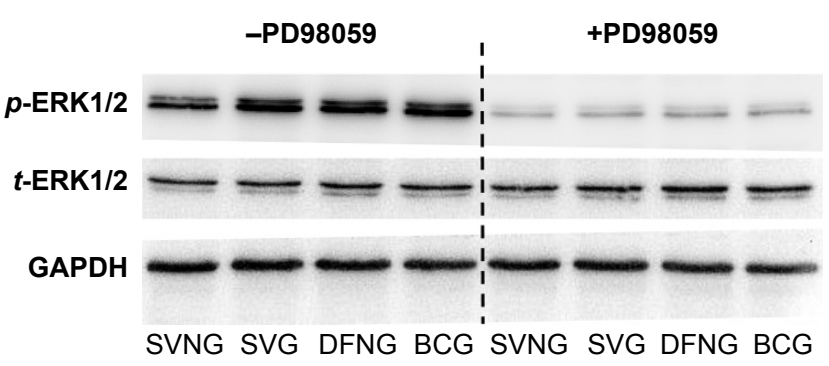

C

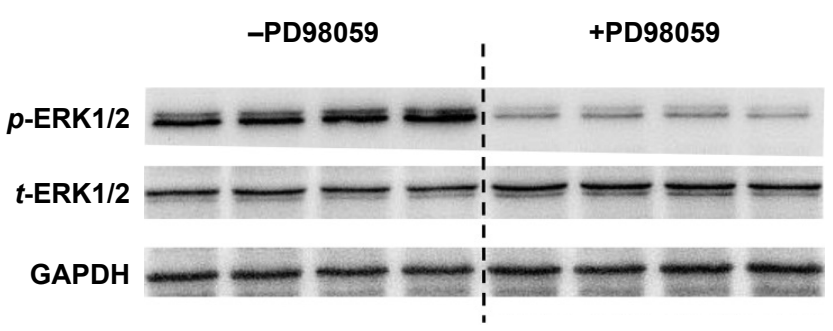

SVNG SVG DFNG BCG SVNG SVG DFNG BCG

D

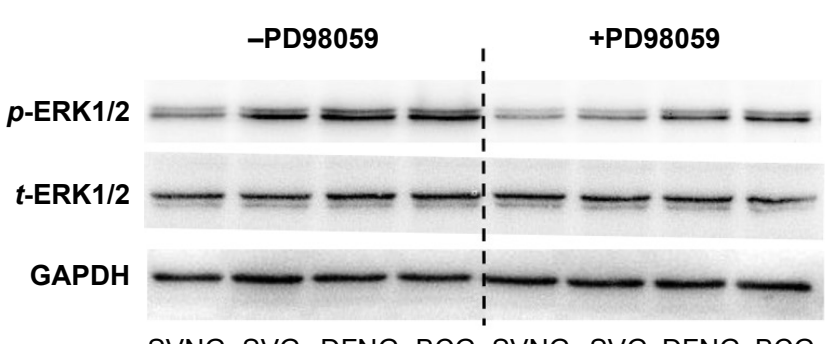

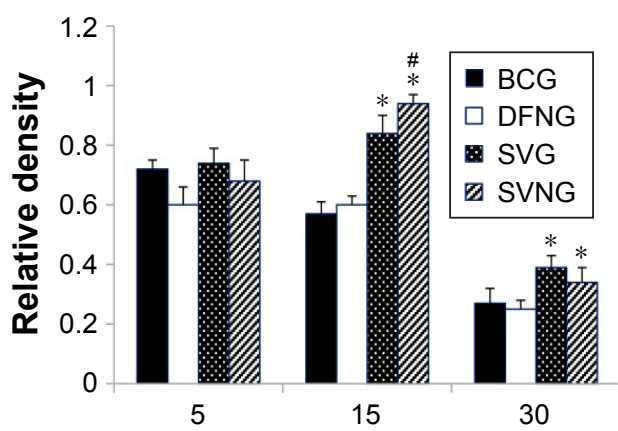

Time (minutes)
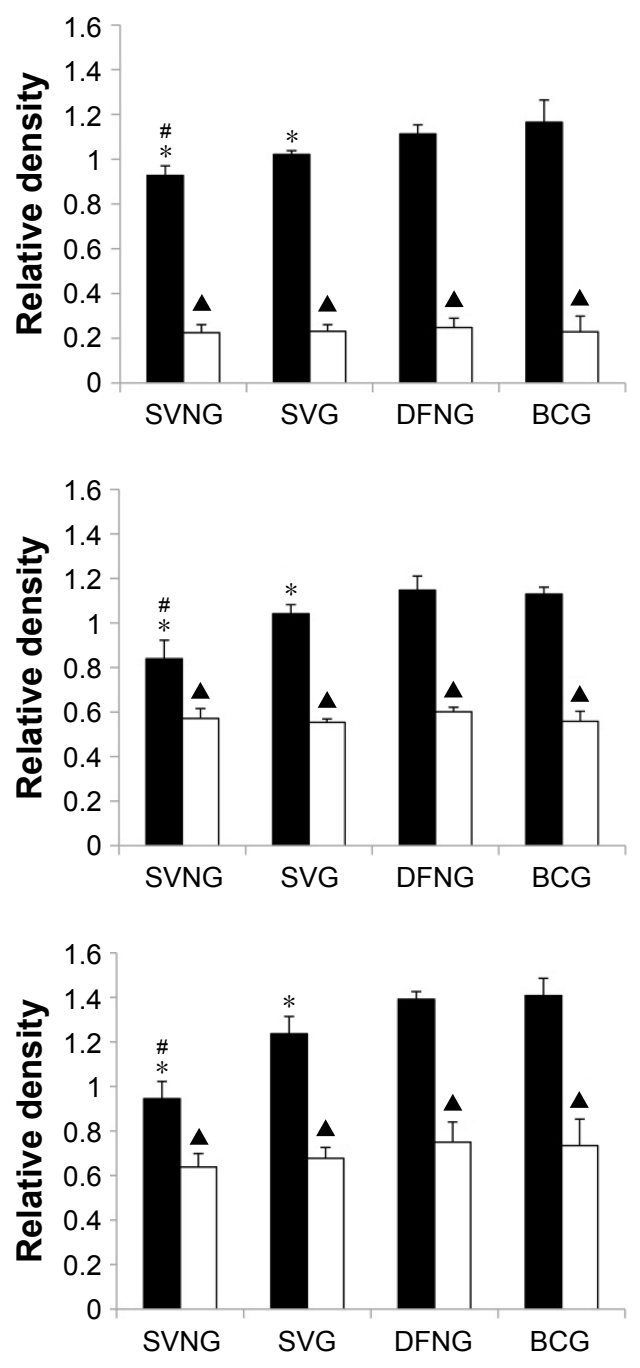

-PD98059 $\square+$ +PD98059

Figure 3 The effects of SVNs and SV on the ERKI/2 pathway.

Notes: SVNs and SV can increase the expression of $p$-ERKI/2 in the early stage of the experiment (A). On I day (B), 7 days (C), and I4 days (D), both SVNs and SV exhibited a significant, sustained inhibitory effect on the expression of the $p$-ERKI/2. In addition, the expression of $p$-ERKI/2 in each experimental group was inhibited significantly after the MG63 cells were pretreated with the ERKI/2 pathway inhibitor PD98059 (50 $\mu \mathrm{M}$ ) prior to drug intervention (B-D). The results are the mean values of three independent measurements ( \pm SD). $* P<0.05$ vs BCG; ${ }^{*} P<0.05$ SVNG vs SVG; ${ }^{\wedge} P<0.05$ drug vs drug + PD 98059.

Abbreviations: BCG, blank control group; DFNG, drug-free nanomicelles group; $p$-ERKI/2, phosphorylated ERKI/2; SD, standard deviation; SV, simvastatin; SVG, simvastatin group; SVNs, simvastatin-loaded nanomicelles; SVNG, simvastatin-loaded nanomicelles group; $t$-ERKI/2, total ERKI/2. 
ERK1/2 proteins (Figure 3B-D). Again, SVNs exhibited a stronger inhibitory effect than SV (Figure 3B-D). In addition, the MG63 cells were pretreated with the ERK1/2 pathway inhibitor PD98059 (50 $\mu \mathrm{M})$ prior to drug intervention. The expression levels of the phosphorylated ERK1/2 proteins were significantly inhibited in the experimental groups compared with the group of MG63 cells that had not been treated with the inhibitor (Figure 3B-D).

\section{Effects of SVNs and SV on cell proliferation and osteogenic differentiation via the ERKI/2 pathway}

To clarify the effects of SVNs and SV on MG63 cell proliferation and osteogenic differentiation via the ERK1/2 pathway, we pretreated the cells with PD98059, and changes in the cell proliferation, cell cycle, cell apoptosis, ALP activity, and OSX and OC protein expression levels were tested.

\section{Cell proliferation}

Figure 4 shows that the number of cells significantly decreased in the SVNG and the SVG at 1 day after administration of the drugs compared to that of the BCG, regardless of whether the ERK1/2 pathway inhibitor PD98059 was added. Moreover, the SVNG had the lowest number of cells, indicating that SVNs exerted a significantly more potent inhibitory effect on cell proliferation than SV. Pretreatment

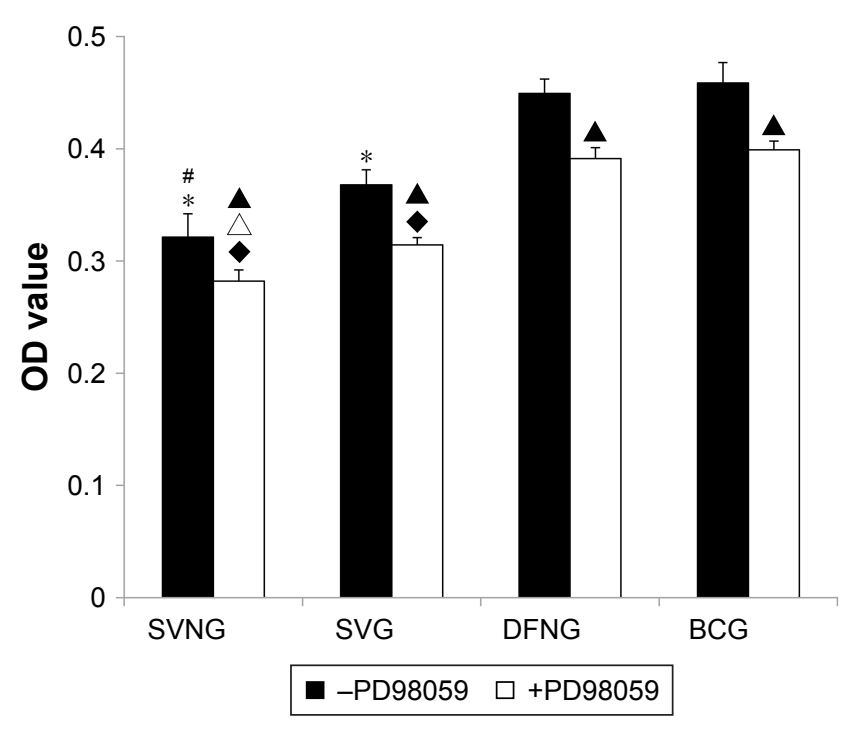

Figure 4 The role of the ERKI/2 pathway in the regulation of cell proliferation by SVNs and SV.

Notes: The results are the mean values of three independent measurements ( \pm SD). $* P<0.05$ vs $B C G ;{ }^{\#} P<0.05$ SVNG vs SVG; ${ }^{\wedge} P<0.05$ drug vs drug + PD98059; $\bullet P<0.05$ vs $B C G+P D 98059 ;{ }^{\Delta} P<0.05$ SVNG + PD98059 vs SVG + PD98059.

Abbreviations: BCG, blank control group; DFNG, drug-free nanomicelles group; SD, standard deviation; SV, simvastatin; SVG, simvastatin group; SVNs, simvastatinloaded nanomicelles; SVNG, simvastatin-loaded nanomicelles group. of the cells with PD98059 further significantly inhibited cell proliferative activity in the experimental groups.

\section{Cell cycle}

To clarify whether the inhibitory effect of SVNs and SV on the proliferative activity of MG63 cells is related to a druginduced alteration of the cell cycle, we used flow cytometry to analyze the cell cycle of the MG63 cells in all experimental groups. Figure 5 shows that the percentages of MG63 cells in the G0/G1 phases of the cell cycle were significantly increased, while the percentages of cells in the $\mathrm{S}$ phase of the cell cycle were markedly reduced in the SVNG and the SVG 1 day after administration of the drugs compared to the BCG, regardless of whether the cells were pretreated with PD98059. In contrast, no significant changes were observed in the percentages of G2/M phase cells. Pretreatment with PD98059 significantly increased the percentages of MG63 cells in the G0/G1 phases of the cell cycle and considerably decreased the percentages of cells in the G2/M phases of the cell cycle in the experimental groups. PD98059 had no significant effect on the percentage of $\mathrm{S}$ phase cells.

\section{Cell apoptosis}

The above cell proliferation experiment results showed that SVNs and SV significantly reduced the number of MG63 cells. To determine whether the decrease in the number of cells in the SVNG and the SVG was related to a druginduced increase in the apoptotic rate of cells, we used flow cytometry to analyze the apoptotic rates of MG63 cells in various experimental groups. Figure 6 shows that SVNs and SV failed to enhance the apoptotic rate of MG63 cells 1 day after drug administration. Pretreatment with PD98059 significantly increased the apoptotic rate in all experimental groups. Compared with the BCG, the SVNG and SVG exhibited a certain degree of inhibition of apoptosis.

\section{ALP activity}

Figure 7A shows that cellular ALP activity was greater in the SVNG and the SVG at 7 days after drug administration than in the BCG, regardless of whether the cells were pretreated with PD98059. Moreover, the SVNG exhibited the greatest cellular ALP activity. Pretreatment with PD98059 significantly increased the cellular ALP activity in all experimental groups.

\section{OSX and OC protein levels}

The OSX and OC protein expression levels in MG63 cells cultured with the same concentration of SVNs and SV were 

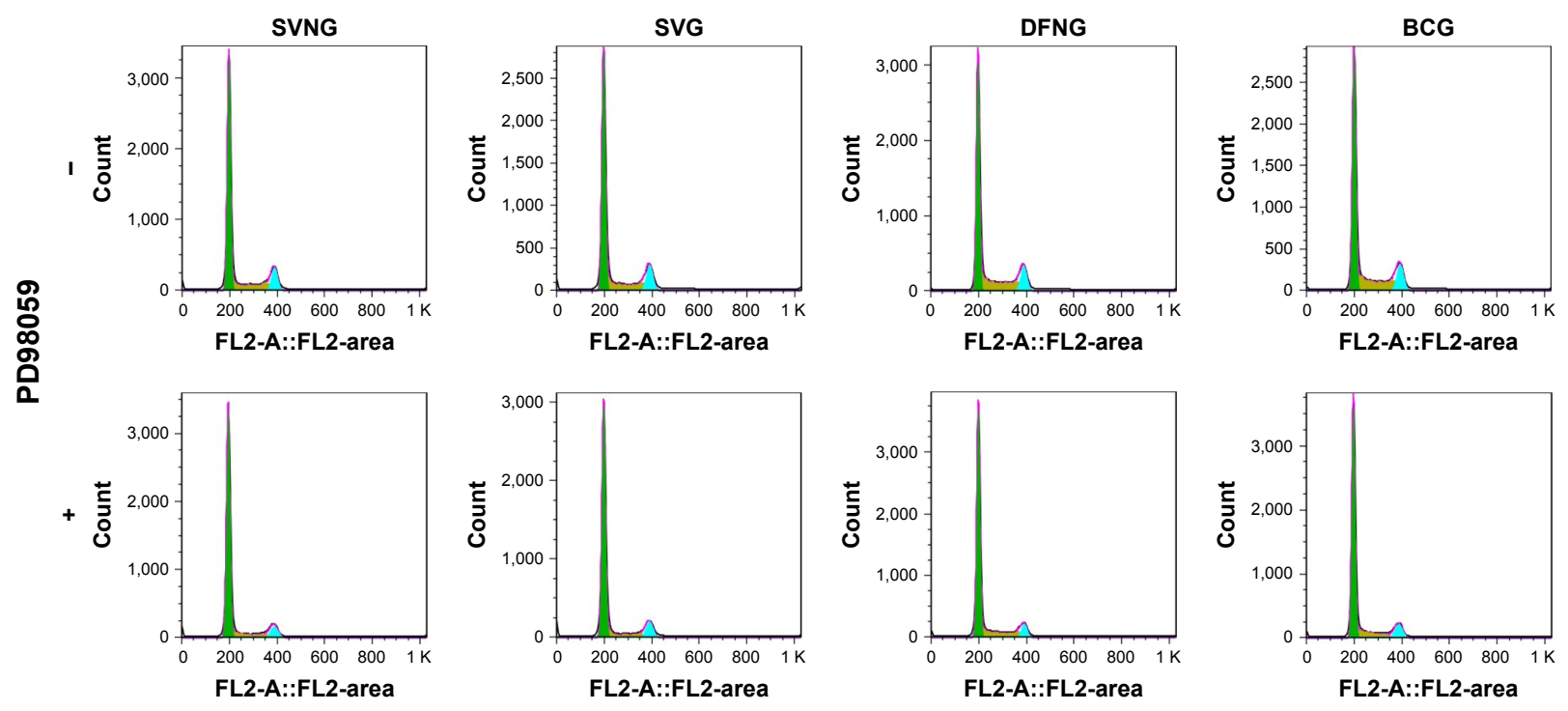

$\square$ G0/G1 phase $\square$ S phase $\quad \square$ G2/M phase

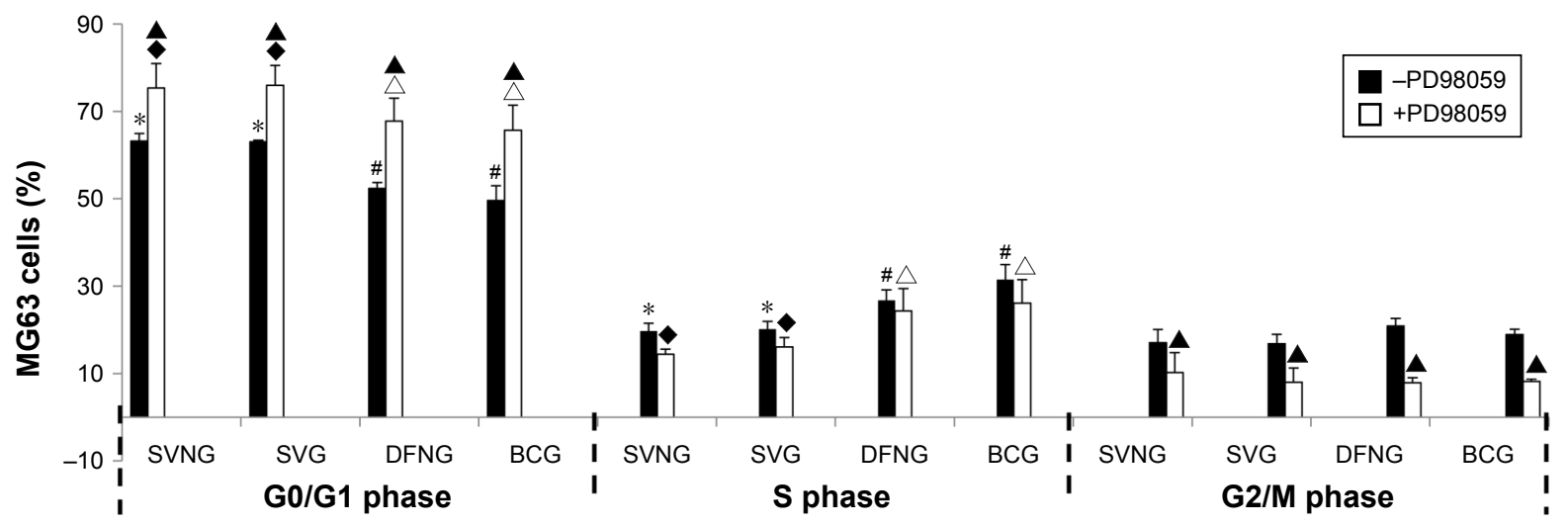

Figure 5 The role of the ERKI/2 pathway in the regulation of the cell cycle by SVNs and SV.

Notes: The results are the mean values of three independent measurements ( \pm SD). $* P<0.05$ vs $B C G ;{ }^{*} P<0.05$ SVNG vs SVG; ${ }^{\wedge} P<0.05$ drug vs drug + PD98059; $\bullet P<0.05$ vs BCG + PD98059; $\triangle P<0.05$ vs SVG + PD98059.

Abbreviations: BCG, blank control group; DFNG, drug-free nanomicelles group; SD, standard deviation; SV, simvastatin; SVG, simvastatin group; SVNs, simvastatin-loaded nanomicelles; SVNG, simvastatin-loaded nanomicelles group.

determined by Western blot analysis. Figure 7B and C shows that the cellular expression of OSX or OC protein was significantly greater in the SVNG and the SVG at 7 or 14 days after drug administration than in the BCG. SVNs further significantly enhanced the SV-promoting effect on OSX or OC expression in MG63 cells. Addition of the PD98059 inhibitor significantly upregulated the cellular expression of OSX or OC protein in all experimental groups.

\section{Discussion}

A growing number of studies have shown that SV promotes bone formation in the jaw by regulating endogenous osteogenic growth factors. ${ }^{67}$ However, $\mathrm{SV}$ is a lipid-soluble drug. The bioavailability of SV is extremely low, and high doses of SV have potential side effects. Solutions to these problems are urgently needed. Encapsulation of hydrophobic drugs in nanocarriers significantly improves the bioavailability of the drugs, prolongs the action time of the drugs, and alleviates the side effects of the drugs. In the present study, SVNs were synthesized using a dialysis method that we optimized in a previous study. The dialysis method has several advantages. The procedure is easy to perform and does not involve any surfactant. In addition, the dialysis method confers a high rate of sphere formation and produces a significant sustainedrelease effect. ${ }^{21}$ The SVNs synthesized in the current study had a small mean diameter, exhibited satisfactory drug encapsulation and loading efficiencies, and were spherical in shape. Compared with SV, SVNs exhibited a significant sustained-release effect. SV was released over a period of 12 hours. SVNs prolonged the duration of SV release 

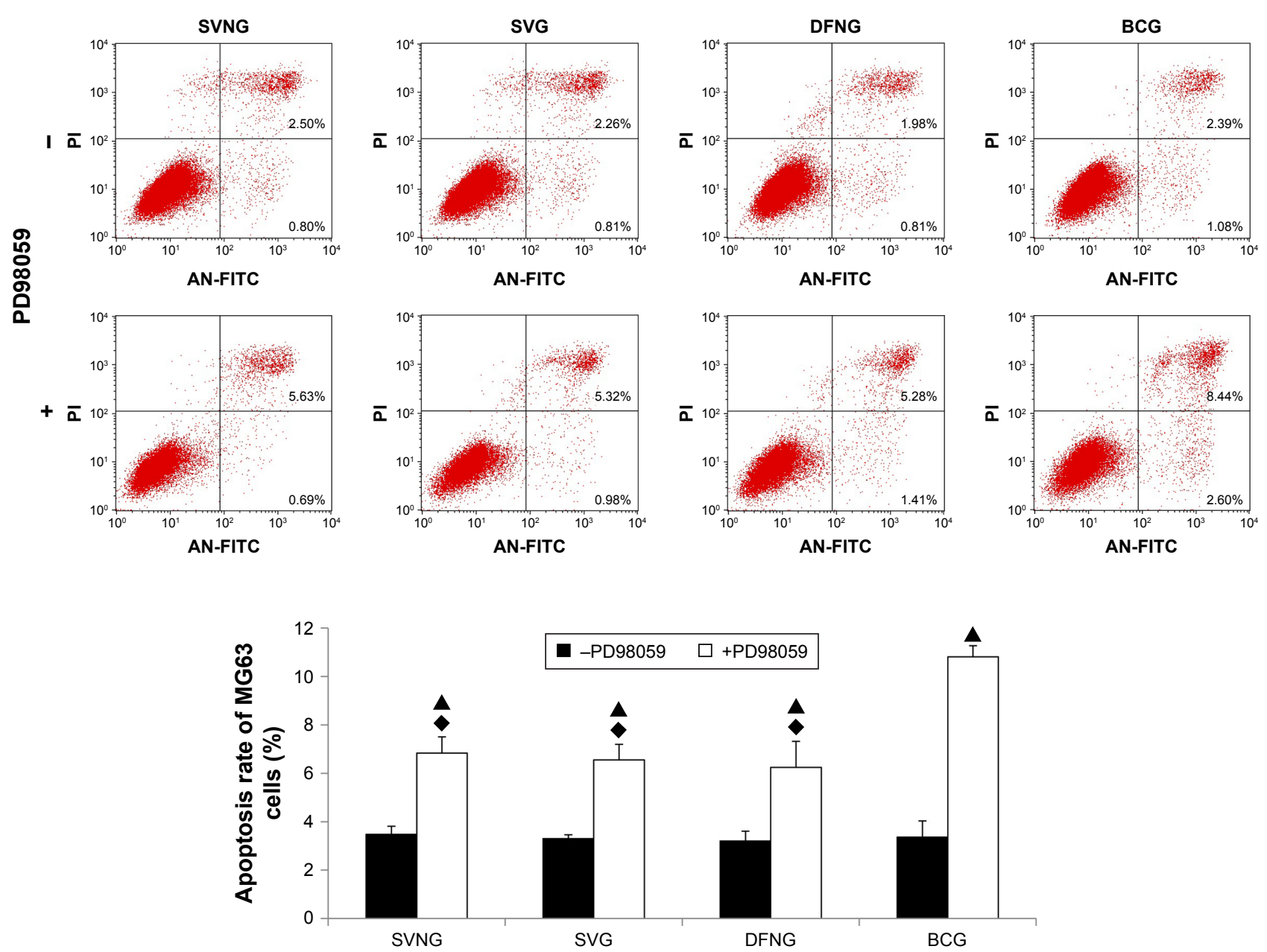

Figure 6 The role of the ERKI/2 pathway in the regulation of cell apoptosis by SVNs and SV. The results are the mean values of three independent measurements ( \pm SD). ${ }^{\wedge} P<0.05$ drug vs drug $+\mathrm{PD} 98059 ; \bullet P<0.05$ vs BCG $+\mathrm{PD} 98059$.

Abbreviations: BCG, blank control group; DFNG, drug-free nanomicelles group; SD, standard deviation; SV, simvastatin; SVG, simvastatin group; SVNs, simvastatin-loaded nanomicelles; SVNG, simvastatin-loaded nanomicelles group.

(same dose of SV) by nearly 10-fold, which allowed SV to exert a long-term osteogenic effect.

Our previous in vitro study showed that SVNs and SV inhibited the proliferative activity of MG63 cells while promoting the osteogenic differentiation of the cells. Currently, most researchers believe that the first step to induce cell differentiation is to stop cell proliferation and induce cell cycle withdrawal in a large number of cells. ${ }^{22}$ In addition, researchers believe that differentiation generally occurs in G1-phase cells. ${ }^{23,24} \mathrm{SV}$ was found to inhibit the transition of cells from the G1 phase to the $\mathrm{S}$ phase of the cell cycle, reduce the number of cells entering mitosis, and decrease the proliferative activity of cells. ${ }^{25}$ The current study confirmed once more that SVNs and SV inhibited the proliferative activity of MG63 cells. Moreover, examination of the cell cycle revealed that SVNs and SV arrested MG63 cells in the G0/G1 phase and significantly reduced the percentage of S-phase cells, resulting in a decrease in cell number. To further determine whether the SVN- and SV-induced decrease in cell number was related to drug-induced apoptosis, we analyzed the apoptotic rate in all experimental groups. We found that SVNs and SV did not stimulate apoptosis. The findings indicate that SVNs and SV inhibited the proliferation of MG63 cells while promoting the osteogenic differentiation of MG63 cells by altering the cell cycle.

In addition, our previous study examined the gene and protein expression of osteogenesis-related factors (such as ALP, OC, and Col I) in MG63 cells and preliminarily demonstrated that SVNs significantly enhanced the osteogenic differentiation-promoting effect of SV in vitro. ${ }^{11}$ Based on these results, the current study examined osteogenesisrelated factors, such as OSX, ALP, and OC, in MG63 cells. The current study further demonstrated that transformation of SV into SVNs effectively enhanced the efficacy of SV 


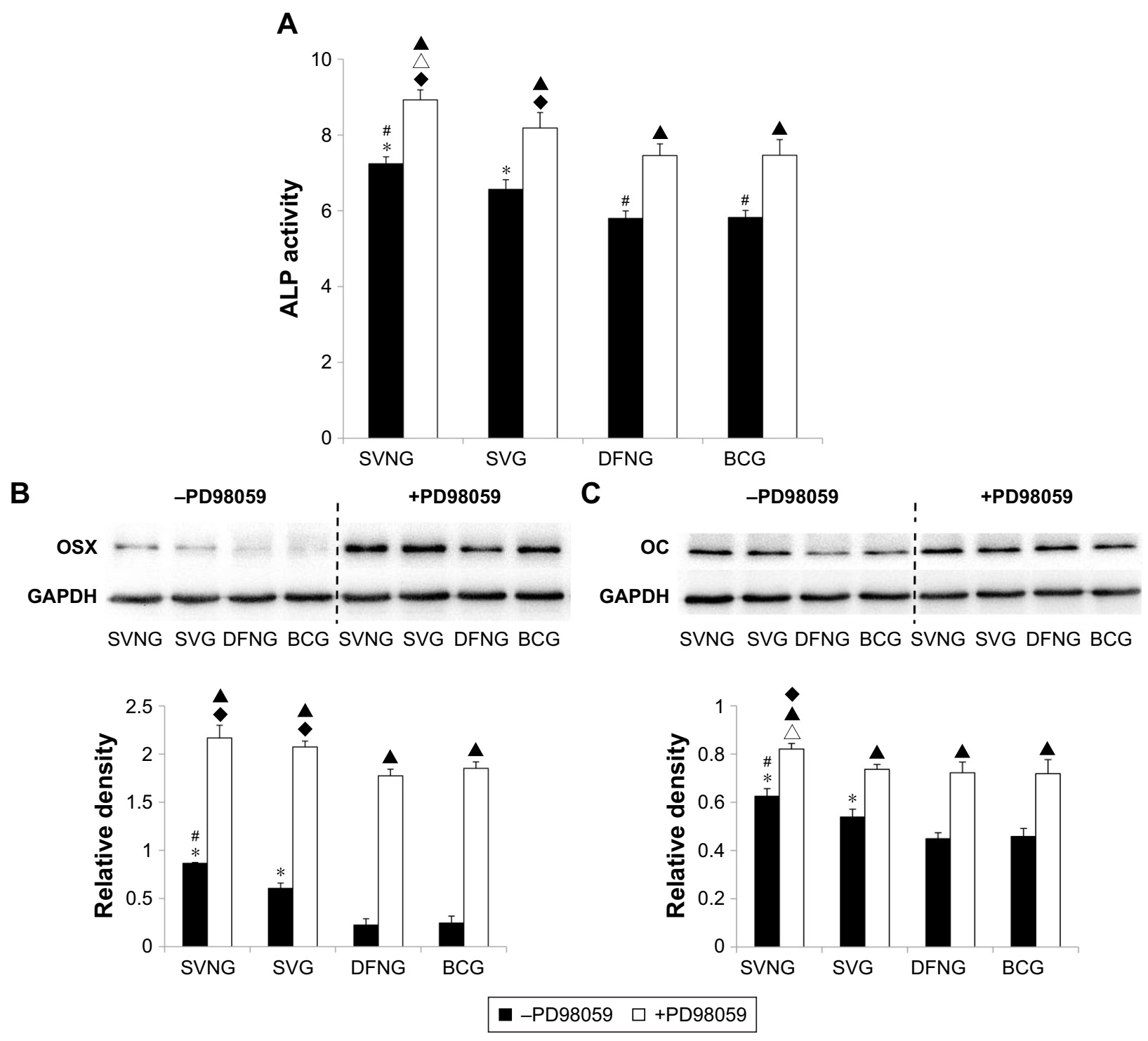

Figure 7 The role of the ERKI/2 pathway in the regulation of osteogenic differentiation of cells by SVNs and SV. By inhibiting the ERKI/2 pathway, SVNs and SV increased the ALP activity (A) and the protein expression levels of OSX (B) and OC (C) in MG63 cells. The results are represented as the mean values of three independent measurements $\left( \pm\right.$ SD). $* P<0.05$ vs BCG; $\# P<0.05$ SVNG vs SVG; ${ }^{\wedge} P<0.05$ drug vs drug + PD98059; ${ }^{*} P<0.05$ vs BCG + PD98059; $\triangle P<0.05$ SVNG + PD98059 vs SVG + PD98059.

Abbreviations: BCG, blank control group; DFNG, drug-free nanomicelles group; OC, osteocalcin; OSX, osterix; SD, standard deviation; SV, simvastatin; SVG, simvastatin group; SVNs, simvastatin-loaded nanomicelles; SVNG, simvastatin-loaded nanomicelles group.

in promoting osteogenesis. Currently, there are very few reports focusing on the mechanisms of why SVNs exhibit a more potent osteogenic differentiation-promoting effect than SV. We speculate that the underlying mechanism might be related to the stronger activating or inhibitory effect of SVNs on certain signaling pathways governing osteogenic differentiation than SV.

MAPKs are present in all eukaryotic cells. MAPKs belong to a large family of serine/threonine protein kinases. MAPK pathways are involved in a variety of important cellular activities, such as mitosis, proliferation, differentiation, and apoptosis. Among the MAPK pathways, the ERK1/2 pathway was discovered first and is the best-studied pathway. Numerous studies have shown that the ERK1/2 pathway is activated at all stages of osteoblast development. But controversies remain surrounding the role of the ERK $1 / 2$ pathway in cell proliferation and osteogenic differentiation. Some scholars found that EGF transiently activated the ERK1/2 pathway in PC12 rat pheochromocytoma cells and thus exhibited a cell proliferation-promoting effect. In contrast, nerve growth factor persistently activated the ERK $1 / 2$ pathway in P12 cells, which inhibited cell proliferation and promoted cell differentiation. Moreover, cell proliferation was promoted when continuous activation of the ERK1/2 
pathway was induced by exposure to extracellular stimuli at appropriate intensities, ${ }^{26}$ whereas excessive activation of the ERK1/2 pathway caused the cell to enter a quiescent state. ${ }^{27}$ In addition, scholars found that BMP-2 promoted osteogenic differentiation by activating the ERK1/2 pathway. Inhibition of ERK1/2 pathway activity resulted in a significant decrease in cellular ALP activity. ${ }^{28}$ However, other studies ${ }^{28-30}$ proposed that activation of the ERK1/2 pathway downregulated the expression of the osteogenesis-related factors (such as BMP-2, Col I, and OC) and negatively regulated osteogenesis. Such controversies may be related to the cell type, the types of extracellular stimuli, the degree of activation, and the duration of activation. In the current study, the cells were treated with PD98059, which is a specific inhibitor of the ERK1/2 pathway. Examination of the changes in cell proliferation and osteogenic differentiation-related indices revealed that inhibition of ERK1/2 pathway activation reduced the proliferative capacity of the cells. In contrast, cellular ALP activity was significantly elevated, OSX and OC protein expression was significantly increased, and the osteogenic differentiation capability of the cells was considerably enhanced. The results indicate that the ERK1/2 pathway mainly plays a negative regulatory role in the osteogenic differentiation of MG63 cells. The results are consistent with the findings of the vast majority of previous studies.

The ERK1/2 pathway is activated by extracellular mitogens, such as growth factors. As a result, the Ras/RafMEK-ERK signaling pathway is initiated, which transmits information to the nucleus, acts on transcription factors, and eventually promotes the transcription and expression of target genes. Statins regulate the activity of the Ras/Raf-MEK-ERK pathway by affecting Ras (the upstream activator protein of the ERK1/2 pathway), thereby regulating the biological properties of the cells. ${ }^{31}$ To date, most studies have reported that SV exerts an inhibitory effect on the ERK1/2 pathway, thereby reducing the severity of myocardial fibrosis in mice suffering from myocardial infarction and promoting the death of breast cancer cells and cholangiocarcinoma cells. ${ }^{32-34}$ However, some scholars have found that SV activates the ERK1/2 pathway. Yamamoto et $\mathrm{al}^{35}$ found that SV activated the ERK1/2 pathway, thereby promoting the secretion of enkephalinase by astrocytes. Cheng et $\mathrm{al}^{36}$ reported that SV upregulated the expression of endothelial nitric oxide synthase by activating the ERK1/2 pathway, thus exerting a central hypotensive effect on hypertensive rats. This discrepancy between experimental results may be related to factors such as cell type, drug concentration, and detection time. In the current study, Western blot analysis was performed to examine the level of the phosphorylated ERK1/2 proteins at various time points. SVNs and SV positively regulated the ERK1/2 pathway in MG63 cells at early time points but negatively regulated the ERK1/2 pathway at late time points. In other words, SVNs and SV exerted a transient activating effect on the ERK1/2 pathway shortly after administration of the drugs. The activating effect was then replaced by a long-term inhibitory effect. Such a phenomenon has not yet been reported, and further investigation is required to determine the underlying mechanisms. In addition, the current study showed that SVNs and SV promoted the osteogenic differentiation of MG63 cells mainly through long-term inhibition of the ERK1/2 pathway. Throughout the whole experimental process, SVNs exhibited a significantly more potent regulatory effect on the ERK1/2 pathway than SV. The stronger regulatory effect of SVNs may be related to their sustained-release property, which allows for the long-term maintenance of an effective drug concentration in the cells. The potent regulatory effect of SVNs may also be related to the unique properties of nanomaterials, such as their small size, large specific surface area, special nanostructures, and strong cell adsorption. The inhibitory effect of SVNs on the ERK1/2 pathway was more potent than that of SV, and this result might represent one of the molecular mechanisms underlying the stronger osteogenic differentiation-promoting effect of SVNs than SV. A limitation of this study is that the activator of the ERK1/2 pathway has not been used to see if the activator can offset the inhibition of SVNs on the ERK1/2 pathway. This section should be analyzed in future studies.

\section{Conclusion}

The present study demonstrated that the ERK1/2 pathway mainly played a negative regulatory role in the osteogenic differentiation of MG63 cells. SVNs and SV inhibited the activation of the ERK1/2 pathway, thereby altering the cell cycle of MG63 cells and arresting the cells in the G0/G1 phase. By inhibiting the ERK1/2 pathway, SVNs and SV reduced the proliferative activity of MG63 cells without increasing the apoptotic rate. SVNs and SV also promoted the osteogenic differentiation of MG63 cells. SVNs displayed a stronger osteogenic differentiation-promoting capability than SV. This phenomenon might be related to the fact that SVNs had a more potent inhibitory effect on the ERK1/2 pathway than SV.

\section{Acknowledgment}

This work was supported by grants from the National Natural Science Foundation of China (No 81170998) and 
the Youth Innovation Projects of Shenzhen Polytechnic (No 601722K31020).

\section{Disclosure}

The authors report no conflicts of interest in this work.

\section{References}

1. Schlee M, Dehner JF, Baukloh K, Happe A, Seitz O, Sader R. Esthetic outcome of implant-based reconstructions in augmented bone: comparison of autologous and allogeneic bone block grafting with the pink esthetic score (PES). Head Face Med. 2014;10(1):21.

2. Man Z, Li T, Zhang L, et al. E7 peptide-functionalized Ti6A14V alloy for BMSC enrichment in bone tissue engineering. Am J Transl Res. 2018 10(8):2480-2490.

3. Al-Nawas B, Schiegnitz E. Augmentation procedures using bone substitute materials or autogenous bone - a systematic review and meta-analysis. Eur J Oral Implantol. 2014;7(Supp1 2):S219-S234.

4. Mundy G, Garrett R, Harris S, et al. Stimulation of bone formation in vitro and in rodents by statins. Science. 1999;286(5446):1946-1949.

5. Allon I, Anavi Y, Allon DM. Topical simvastatin improves the proangiogenic and pro-osteogenic properties of bioglass putty in the rat calvaria critical-size model. J Oral Implantol. 2014;40(3):251-258.

6. Mansour G, Al Ashwah A, Koura A. Evaluation of simvastatin grafting around immediate dental implants in dogs. Implant Dent. 2014;23(2): 195-199.

7. Sezavar M, Bohlouli B, Farhadi S, Tabatabaee S, Latifi R. Simvastatin effects on dental socket quality: a comparative study. Contemp Clin Dent. 2018;9(1):55-59.

8. Hu F, Zhang XY, Wang CX, Zhou L. [Effects of Simvastatin on osteoblast activity of human periodontal ligament cells]. Hua Xi Kou Qiang Yi Xue Za Zhi. 2009;27(3):313-316. Chinese [with English abstract]

9. Schachter M. Chemical, pharmacokinetic and pharmacodynamic properties of statins: an update. Fundam Clin Pharmacol. 2005;19(1):117-125.

10. Charles-Schoeman C, Amjadi SS, Paulus HE; International Myositis Assessment and Clinical Studies Group. Treatment of dyslipidemia in idiopathic inflammatory myositis: results of the International Myositis Assessment and Clinical Studies Group survey. Clin Rheumatol. 2012;31(8):1163-1168.

11. Liu X, Li X, Zhou L, et al. Effects of simvastatin-loaded polymeric micelles on human osteoblast-like MG-63 cells. Colloids Surf B Biointerfaces. 2013;102:420-427.

12. Yue $X$, Niu M, Zhang $T$, et al. In vivo evaluation of a simvastatin-loaded nanostructured lipid carrier for bone tissue regeneration. Nanotechnology. 2016;27(11):115708.

13. Boulton TG, Yancopoulos GD, Gregory JS, Slaughter C, Moomaw C, Hsu J, Cobb MH. An insulin-stimulated protein kinase similar to yeast kinases involved in cell cycle control. Science. 1990;249(4964): 64-67.

14. Boulton TG, Nye SH, Robbins DJ, et al. ERKs: a family of proteinserine/threonine kinases that are activated and tyrosine phosphorylated in response to insulin and NGF. Cell. 1991;65(4):663-675.

15. Pearson G, Robinson F, Beers Gibson T, Xu BE, Karandikar M, Berman K, Cobb MH. Mitogen-activated protein (MAP) kinase pathways: regulation and physiological functions. Endocr Rev. 2001;22(2): 153-183.

16. Widmann C, Gibson S, Jarpe MB, Johnson GL. Mitogen-activated protein kinase: conservation of a three-kinase module from yeast to human. Physiol Rev. 1999;79(1):143-180.

17. Klees RF, Salasznyk RM, Kingsley K, Williams WA, Boskey A, Plopper GE. Laminin-5 induces osteogenic gene expression in human mesenchymal stem cells through an ERK-dependent pathway. Mol Biol Cell. 2005;16(2):881-890.
18. Byun MR, Kim AR, Hwang JH, Kim KM, Hwang ES, Hong JH. FGF2 stimulates osteogenic differentiation through ERK induced TAZ expression. Bone. 2014;58(1):72-80.

19. Zeng W, Yan Y, Zhang F, Zhang C, Liang W. Chrysin promotes osteogenic differentiation via ERK/MAPK activation. Protein Cell. 2013; 4(7):539-547.

20. Casey PJ, Seabra MC. Protein prenyltransferases. J Biol Chem. 1996; 271(10):5289-5292.

21. Letchford K, Burt H. A review of the formation and classification of amphiphilic block copolymer nanoparticulate structures: micelles, nanospheres, nanocapsules and polymersomes. Eur J Pharm Biopharm. 2007;65(3):259-269.

22. Linskey ME, Gilbert MR. Glial differentiation: a review with implications for new directions in neuro-oncology. Neurosurgery. 1995; 36(1):1-22.

23. Herwig S, Strauss M. The retinoblastoma protein: a master regulator of cell cycle, differentiation and apoptosis. Eur J Biochem. 1997; 246(3):581-601.

24. Pestell RG, Albanese C, Reutens AT, Segall JE, Lee RJ, Arnold A. The cyclins and cyclin-dependent kinase inhibitors in hormonal regulation of proliferation and differentiation. Endocr Rev. 1999;20(4):501-534.

25. Sala SG, Muñoz U, Bartolomé F, Bermejo F, Martín-Requero A. HMG-CoA reductase inhibitor simvastatin inhibits cell cycle progression at the G1/S checkpoint in immortalized lymphocytes from Alzheimer's disease patients independently of cholesterol-lowering effects. J Pharmacol Exp Ther. 2008;324(1):352-359.

26. Chambard JC, Lefloch R, Pouysségur J, Lenormand P. ERK implication in cell cycle regulation. Biochim Biophys Acta. 2007;1773(8): 1299-1310.

27. Coleman ML, Marshall CJ, Olson MF. Ras promotes p21(Waf1/Cip1) protein stability via a cyclin D1-imposed block in proteasome-mediated degradation. EMBO J. 2003;22(9):2036-2046.

28. Higuchi C, Myoui A, Hashimoto N, Kuriyama K, Yoshioka K, Yoshikawa H, Itoh K. Continuous inhibition of MAPK signaling promotes the early osteoblastic differentiation and mineralization of the extracellular matrix. J Bone Miner Res. 2002;17(10):1785-1794.

29. Kretzschmar M, Doody J, Massagué J. Opposing BMP and EGF signalling pathways converge on the TGF-beta family mediator Smad1. Nature. 1997;389(6651):618-622.

30. Chaudhary LR, Avioli LV. Extracellular-signal regulated kinase signaling pathway mediates downregulation of type I procollagen gene expression by FGF-2, PDGF-BB, and okadaic acid in osteoblastic cells. $J$ Cell Biochem. 2000;76(3):354-359.

31. Chen PY, Sun JS, Tsuang YH, Chen MH, Weng PW, Lin FH. Simvastatin promotes osteoblast viability and differentiation via Ras/Smad/ Erk/BMP-2 signaling pathway. Nutr Res. 2010;30(3):191-199.

32. Sun F, Duan W, Zhang Y, et al. Simvastatin alleviates cardiac fibrosis induced by infarction via up-regulation of TGF- $\beta$ receptor III expression. Br J Pharmacol. 2015;172(15):3779-3792.

33. Wang T, Seah S, Loh X, et al. Simvastatin-induced breast cancer cell death and deactivation of PI3K/Akt and MAPK/ERK signalling are reversed by metabolic products of the mevalonate pathway. Oncotarget. 2016;7(3):2532-2544

34. Lee J, Hong EM, Jang JA, et al. Simvastatin induces apoptosis and suppresses insulin-like growth factor 1 receptor in bile duct cancer cells. Gut Liver. 2016;10(2):310-317.

35. Yamamoto N, Fujii Y, Kasahara R, et al. Simvastatin and atorvastatin facilitates amyloid $\beta$-protein degradation in extracellular spaces by increasing neprilysin secretion from astrocytes through activation of MAPK/Erk1/2 pathways. Glia. 2016;64(6):952-962.

36. Cheng WH, Ho WY, Chang CF, et al. Simvastatin induces a central hypotensive effect via Ras-mediated signalling to cause eNOS upregulation. Br J Pharmacol. 2013;170(4):847-858. 


\section{Publish your work in this journal}

The International Journal of Nanomedicine is an international, peerreviewed journal focusing on the application of nanotechnology in diagnostics, therapeutics, and drug delivery systems throughout the biomedical field. This journal is indexed on PubMed Central,

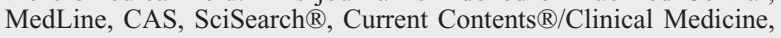

Journal Citation Reports/Science Edition, EMBase, Scopus and the Elsevier Bibliographic databases. The manuscript management system is completely online and includes a very quick and fair peer-review system, which is all easy to use. Visit http://www.dovepress.com/ testimonials.php to read real quotes from published authors.

Submit your manuscript here: http://www.dovepress.com/international-journal-of-nanomedicine-journal 